\title{
Structural Analysis of Platinum Nanoparticles on Carbon Nanotube Surface as Electrocatalyst System
}

\author{
Sudirman ${ }^{1,2}$, Indriyati ${ }^{3}$, Wisnu Ari Adi $^{1}$, Rike Yudianti $^{4}$, Emil Budianto $^{2}$ \\ ${ }^{1}$ Center for Science and Technology of Advanced Material, National Nuclear Energy Agency Serpong 15314, Tangerang \\ Selatan, Indonesia \\ ${ }^{2}$ Department of Chemistry, University of Indonesia Kampus UI Baru, Depok, Indonesia \\ ${ }^{3}$ Research Unit for Clean Technology- Indonesian Institute of Science Jl. Sangkuriang 154D, Bandung, Indonesia \\ ${ }^{4}$ Research Center for Physics- Indonesian Institute of Science Kawasan Puspiptek Serpong-Tangerang Selatan, Banten \\ 15314, Indonesia \\ Correspondence: Sudirman, Center for Science and Technology of Advanced Material, National Nuclear Energy \\ Agency Serpong 15314, Tangerang Selatan, Indonesia.
}

Received: February 3, $2017 \quad$ Accepted: March 6, $2017 \quad$ Online Published: April 4, 2017

doi:10.5539/ijc.v9n2p60 URL: https://doi.org/10.5539/ijc.v9n2p60

\begin{abstract}
Synthesis of Pt/CNT composite by using sol gel method has been performed which the composition of CNT on the composite are vary, $(\mathrm{x}=20,40,60$ and $80 \mathrm{wt} \%)$. Performance of composite was characterized by Transmission Electron Microscope (TEM) and X-Ray Diffraction (XRD), respectively. In the refinement results of X-ray diffraction pattern, the composite consists of two phases, namely, carbon and platinum phases. Carbon phase has a structure hexagonal (P $63 \mathrm{~m} \mathrm{c}$ ) with lattice parameters $\mathrm{a}=\mathrm{b}=2.451(2) \AA$ and $\mathrm{c}=6.89$ (1) $\AA, \alpha=\beta=90^{\circ}$ and $\gamma=120^{\circ}$, the unit cell volume of $\mathrm{V}=35.8(1) \mathrm{A}^{3}$, and the atomic density of $\rho=2.224 \mathrm{~g} . \mathrm{cm}^{-3}$. While platinum phase has the structure of cubic (F m -3 m) with lattice parameters $\mathrm{a}=\mathrm{b}=\mathrm{c}=3.921(2) \AA, \alpha=\beta=\gamma=90^{\circ}$, the unit cell volume of $\mathrm{V}=60.3(1) \mathrm{A}^{3}$, and the atomic density of $\rho=21.487 \mathrm{~g} . \mathrm{cm}^{-3}$.According to the image of TEM, the average particle size for Pt nano particle is estimated to range from 4.1-4.3 $\mathrm{nm}$. While the cavity diameter average of CNT is estimated to range from 5.9-7.5 nm. Based on the calculation, the crystallite size of the Pt particle was around $4.31 \mathrm{~nm}$. The optimum value of dispersed Pt into CNT occurred at $60 \mathrm{wt} \%$ CNT with the best composition of Pt in the unit cell of cystal structure. We concluded that this study successfully dispersed Pt nanoparticles onto CNT formed Pt/CNT composite. This was a great opportunity that the composite can be applied as electrocatalyst system on fuel cell application.
\end{abstract}

Keywords: Pt/CNT, sol-gel method, fuel cell

\section{Introduction}

It is well known that Proton Exchange Membrane Fuel Cell (PEMFC) is a promising device for a secure and clean energy storage that converts a fuel into electrical energy through electrochemical reaction with oxygen or another oxidizing agent (Luo et al., 2015; Debe, 2012; Zhao et al., 2015). Fuel cell is considered as one of the most promising product of 21st century as prospective system which will compete in the efficiency with other conventional combustion engine, batteries. Many of the major challenges in PEM fuel cell commercialization are closely related to three critical considerations: cost, durability, and performance

Untill now, Pt metal are known as electrocatalyst. Some ways have been developed lately to be able to increase the activity of the catalyst. Utilization of carbon nanotube (CNT) as catalyst support is alternative way to increase the activity of Pt and reduce the use of Pt in fuel cells (Wu et al., 2010; Aouissi et al., 2014; Valenzuela-Mu niz et al., 2014; Shi et al., 2014) whereas CNT iscommonly-adopted materials providing the highest activity for electrode reactions and lifetime stability.It has been proven that the use of CNTs as the support of Pt catalysts can increase the oxygen reduction reaction (ORR) activity than carbon black (Rao \& Viswanathan, 2010; Wan et al., 2015; Rao \& Ishikawa, 2012). However, CNTs are inert materials that are difficult to disperse in solution due to high Van der Waals energy. The impurities such as metal catalyst, amorphous carbon and graphite nano-particles can decrease dispersion capability of CNT.

In the current research, variation of concentration of CNT was carried out to know a effectiveness of concentration on the catalytic performance. Preparing good dispersion CNT using $\mathrm{NaBH}_{4}$ as reducing agent is also performed by finding 
good dispersion CNT. Distribution of transition metal nanoparticles on the carbon surface determine the performance of the electrocatalyst in terms of adsorption-desorption of hydrogen, and mass transfer in the electrode system. We selected reducing agent, $\mathrm{NaBH} 4$ to investigate the effectiveness of $\mathrm{NaBH}_{4}$ strength on the reducing in different concentration of CNT.

\section{Experimental Section}

\subsection{Materials}

Multi-wall carbon nanotubes (MWCNTs) were purchased from Chengdu Alpha Nano Tech. Co. Ltd. with purity level of $95 \%$, outer diameter (OD) of $50 \mathrm{~nm}$ and length $5 \mathrm{~m}$ utilized as electrocatalyst carbon supported. Sodium borohydrate $\left(\mathrm{NaBH}_{4}\right)$ as reducing agent used in the Pt/CNT synthesis was selected to deposit Pt nanoparticle onto CNT at $\mathrm{pH}$ 13.Two homogeneous solutions were prepared; the first solution is a precursor consisting of $30 \mathrm{mg}$ of platinic acid $\left(\mathrm{H}_{2} \mathrm{PtCl}_{6}\right)$ and $15 \mathrm{~mL}$ reducing agent. Second solution consisted of $50 \mathrm{mg}$ of cetyl trimethyl ammonium bromide (CTAB) were dissolved in $25 \mathrm{~mL}$ of water and then sonificated for 1 hour. Subsequently, they were added $40 \mathrm{mg}$ of CNTs and sonificated back for 2 hours.

\subsection{Instrumentation}

The qualitative and quantitative analysis was carried out using the X-ray diffraction (XRD) PW1710 Phillips diffractometer equipped with a tube provided with copper anode. X-ray beam was subjected to the sample using $\mathrm{Cu}-\mathrm{K} \alpha$ source $\lambda=1.54 \AA$ ) to obtain spectra ofelectrocatalyst. The diffraction angle was scanned from 10 to $100^{\circ}$ at scanning speed of $5 \% \mathrm{~min}$. The Rietveld analysis was performed applying GSAS program (Toby, 2001; Idris \& Osman, 2013) . The pseudovoigt function was used for describing diffraction line profiles at Rietveld refinement (Toby, 2001). Based on the refinement result, structure parameter (lattice parameters, unit cell volume, atomic density, and mass fraction of each phase) were obtained all. Confirmation of Pt crystallite size was calculated by Williamson Hull method of X-ray diffraction pattern. The Hull Williamson formula is defined asfollows(Idris \& Osman, 2013):

$$
\begin{aligned}
& \text { FWHM (rad) } \operatorname{Cos} \theta=[\mathrm{K} \lambda / \mathrm{D}]+4 \varepsilon \operatorname{Sin} \theta \\
& \text { FWHM = full width half maximum of the peak } \\
& \mathrm{K}=\text { Scherrer constant, } \\
& \lambda=\mathrm{X} \text {-ray wavelength, } \\
& \mathrm{D}=\text { diameter of the crystallites, and } \\
& \varepsilon \quad=\text { lattice strain }
\end{aligned}
$$

The surface morphology and elemental identification of the sample are analyzed by using the JEOL JSM 6510 scanning electron microscope (SEM) and energy dispersive spectroscopy (EDS), respectively. Sample with dimension about 20 $\mathrm{mm}^{2}$ and then gold coated samples were prepared for surface analysis by SEM-EDS at the operating voltage $20 \mathrm{kV}$.

Nanostructure distributions were observed by using transmission electron microscopy (TEM), JEOL JEM 1400. The working principle of TEM in a nutshell is the electron beam illuminating the specimen and produce a image above phosphorus screen. The observation condition are 800,000 times for magnification at a voltage of $120 \mathrm{kV}$.

\subsection{Preparation}

The two solutions were mixed and $\mathrm{pH}$ was adjusted to 13 by addition of $1 \mathrm{M} \mathrm{NaOH}$. Refluxing was performed at $140{ }^{\circ} \mathrm{C}$ for 3 hours. After refluxing, the solution was cooled down and $\mathrm{pH}$ remained at 13 . Sample was then acidified by addition of $0.1 \mathrm{M}$ hydrochloric acid $(\mathrm{HCl})$ until $\mathrm{pH}$ reached 2 and stirred overnight. Neutralization of sample was carried out by filtration and washing with water continuously until neutral condition. The neutral electrocatalyst was then dried overnight in oven at $60^{\circ} \mathrm{C}$. Structural analysis of samples was performed to know the perfomance of electrocatalyst using different reducing agents, $\mathrm{NaBH}_{4}$ and $\mathrm{LiAlH}_{4}$.

\section{Results and Discussion}

\subsection{X-ray Diffraction (XRD) Characterization}

$X$-ray diffraction of the CNT/Pt composites with various of CNT content $(x=20,40,60$ and $80 \mathrm{wt} \%)$ are shown in Figure 1. 


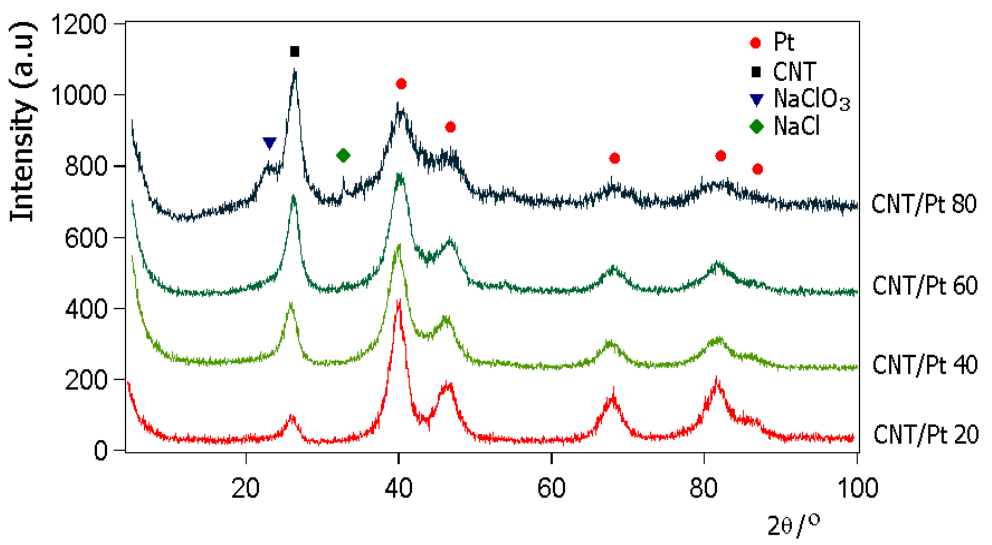

Figure 1. Identification of X-ray Diffraction Pattern of the CNT/Pt with various of CNT content $(x=20,40,60$ and 80 $\mathrm{wt} \%)$

Fig. 1 shows differences on diffraction pattern of electrocatalyst. Four phases on Pt/ CNT 80 appear as Pt; CNT; $\mathrm{NaClO}_{3}$ and $\mathrm{NaCl}$ at 2 Otherwise samples Pt/CNT 20,40, 60 show only two phases as Pt and CNT at 2 in the meaning of Pt/CNT composites have been well established (Monshi et al., 2012; Aritonang et al., 2014; Sharma et al., 2014; Yudianti \& Onggo, 2012). However since Hanawalt table is only able to identify qualitatively (Fig. 1), it would require further analysis to determine the quantitatively phase composition that contained in the composite using the GSAS (General Structure Analysis System) Program. The quantitative analysis refers to the Crystallography Open Database with the card number (COD: 9013417), (COD: 9012705), (COD: 1010513) and (COD: 9008678) respective for phases of Pt, $\mathrm{C}, \mathrm{NaClO}_{3}$ and $\mathrm{NaCl}$.Refinement of XRD pattern of the CNT/Pt composites with various of CNT content $(\mathrm{x}=20$, 40, 60 and $80 \mathrm{wt} \%$ ) using GSAS program was conducted. The refinement of X-ray diffraction pattern has a very good fitting quality based on the criteria of fit $\left(\mathrm{R}_{\mathrm{wp}}\right)$ and goodness of fit $\left(\chi^{2}\right)$ in accordance with the agreement. $\mathrm{R}_{\mathrm{wp}}$ is the weight ratio pattern of the difference between the XRD pattern of observation and calculation (ideal value of $R_{w p}<10 \%$ ). Whereas $\chi^{2}$ (chi-squared) is the ratio of the XRD pattern of observation in which comparable with expectations (ideal value of $1<\chi^{2}<1.3$ )(Toby, 2001).The refinement results of X-ray diffraction pattern shows various of CNT content ( $\mathrm{x}$ $=20,40,60$ and $80 \mathrm{wt} \%$ ) are a composite with mass fraction (the amount of dispersed Pt into CNT) as shown in Fig. 2.

In Fig. 2 is shown the amount of dispersed Pt into CNT based on the refinement result of Pt/CNT XRD profiles.

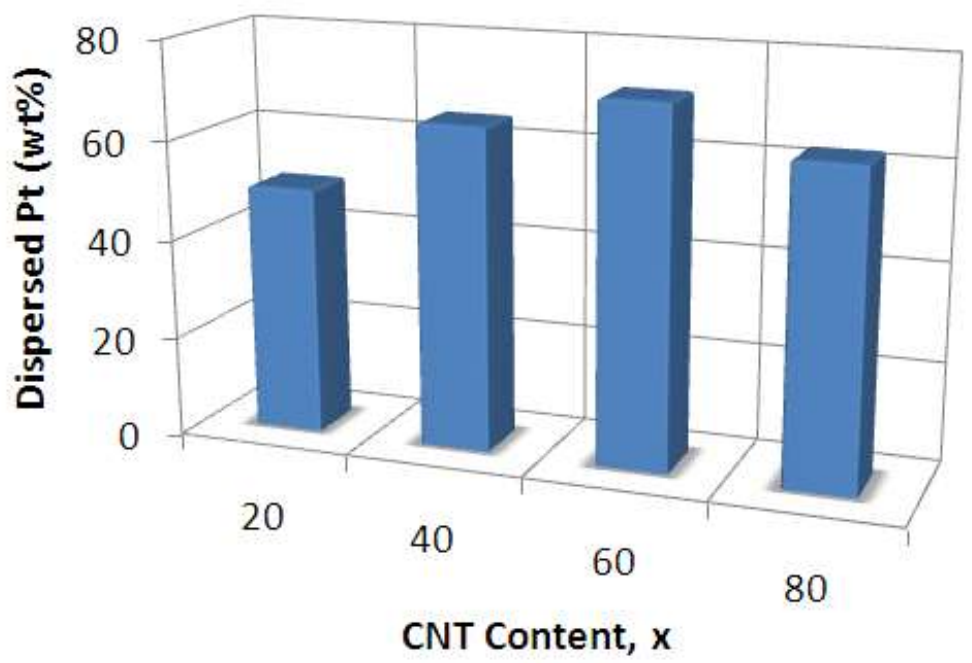

Figure 2. Curve of dispersed Pt on CNT Surface

Doping concentration (x) up to $\mathrm{x}=60$ causes increasing amount of dispersed Pt on CNT surface also increasing on the samples, and then addition furthermore the dispersed Pt into CNT decrease. This indicated that the optimum value of dispersed Pt onto CNT occurred at $60 \mathrm{wt} \%$ CNT content. This case is caused by CNTs are inert materials that are difficult dispersed in solution due to Van der Waals energy is very high. The impurities such as metal catalyst, amorphous carbon and graphite nanoparticles can decrease dispersion capability of CNT. Results on the dispersed Pt into CNTs on these compositions appear larger $(4.1-4.3 \mathrm{~nm})$ compared with the results of research conducted by Jiehua 
(Yudianti \& Onggo, 2012). They have successfully prepared Pt/CNT composites using the solid state method with dispersed Pt $(\sim 30 \mathrm{wt} \%)$ into CNTs. This means that the sample results of this synthesis is expected to have better performance.

The result is supported by changes in the unit cell volume and the atomic density of the CNT (Fig. 3).In Fig. 3 is shown that the maximum atomic density and minimum volumes of unit cells in the sample are obtained at Pt/CNT 60. This indicates that increasing the atomic density was caused decreasing the unit cell volume indicating good Pt dispersion into CNTs occurred. On the composition of Pt/CNT 60, the presence of Pt nanoparticles supposedly forms a perfect shape of a hexagonal crystal of CNT. The assumption is supported on the results of the structure parameters refinement phase XRD pattern CNT (Table 1) approaching the reference structure parameters (COD: 9012705).

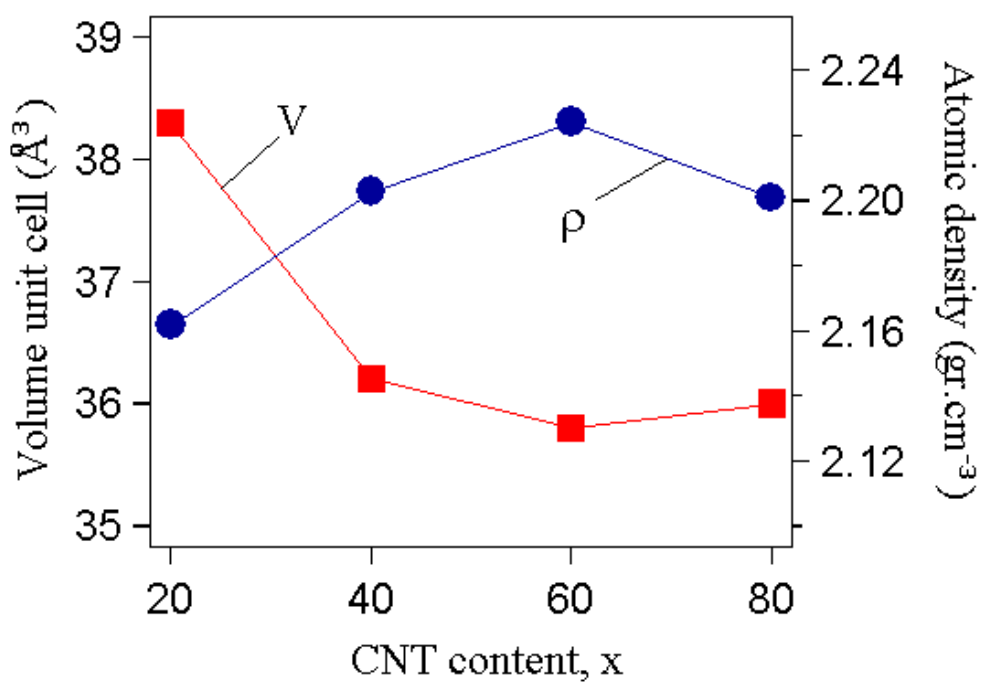

Figure 3. Volume of unit cell and atomic density as functionof CNT content

In accordance to Fig. 3 the optimum value of dispersed Pt into CNT occurred at 60 wt $\%$ CNT content because of the best unit cell volume and atomic density at the composition. For further analysis, this study focused at the composition of Pt/CNT 60. Structure parameter on the composition of Pt/CNT 60 was calculated using the GSAS program based on crystallographic data that carbon structure has the hexagonal lattice with space group: P $63 \mathrm{~m} \mathrm{c}$ (186) and point group of $6 \mathrm{~mm}$. Atomic positions of C(1), and C(2) occupied Wyckoff position of 2a and 2b. A hexagonal unit cell contains two atoms $\mathrm{C}(1)$ and $\mathrm{C}(2)$. While platinum structure had cubic lattice with space group: $\mathrm{F} \mathrm{m}-3 \mathrm{~m}$ (225) and point group of $\mathrm{m} 3 \mathrm{~m}$. Atomic positions of Pt occupied Wyckoff position of $4 \mathrm{a}$. A cubic unit cell contains four atoms Pt. The structure parameter, factor R and goodness of fit $\left(\chi^{2}\right)$ of Pt/CNT 60 are showed in Table 1.

Tabel 1. The structure parameter, factor $\mathrm{R}$ and goodness of fit $(\chi 2)$ Carbon phase

\begin{tabular}{|c|c|}
\hline \multicolumn{2}{|c|}{ Space group : P 63 m c (186), Crystal system: Hexagonal } \\
\hline Refinement result (GSAS) & Reference (COD: 9012705) \\
\hline Lattice parameter: & Lattice parameter: \\
\hline$a=b=2.451(2) \AA$ and $c=6.89(1) \AA$, & $a=b=2.47 \AA$ and $c=6.80 \AA$, \\
\hline$\alpha=\beta=90^{\circ}$ and $\gamma=120^{\circ}$ & $\alpha=\beta=90^{\circ}$ and $\gamma=120^{\circ}$ \\
\hline $\mathrm{V}=35.8(1) \AA^{3}$ and $\rho=2.224$ gr.cm $^{-3}$ & $\mathrm{~V}=35.9 \AA^{3}$ and $\rho=2.22{\mathrm{gr} . \mathrm{cm}^{-3}}^{-3}$ \\
\hline \multicolumn{2}{|l|}{ Platinum phase } \\
\hline \multicolumn{2}{|c|}{ Space group : F m -3 m (225), Crystal system: Cubic } \\
\hline Refinement result (GSAS) & Reference (COD: 9013417) \\
\hline Lattice parameter: & Lattice parameter: \\
\hline$a=b=c=3.921(2) \AA$, & $a=b=c=3.92 \AA$, \\
\hline$\alpha=\beta=\gamma=90^{\circ}$ & $\alpha=\beta=\gamma=90^{\circ}$ \\
\hline $\mathrm{V}=60.3(1) \AA^{3}$ and $\rho=21.487$ gr.cm $\mathrm{cm}^{-3}$ & $\mathrm{~V}=60.4 \AA^{3}$ and $\rho=21.37 \mathrm{gr} . \mathrm{cm}^{-3}$ \\
\hline Factor $\mathrm{R}$ & $\mathrm{R}_{\mathrm{wp}}=8.51 \quad \chi^{2}$ (chi-squared) $=1.018$ \\
\hline
\end{tabular}




\subsection{Energy Dispersive Spectroscopy (EDS) and Transmission Electron Miscroscopy (TEM) Analysis}

The surface morphology and analysis of the elemental content in the Pt/CNT 60 sample were observed by energy dispersive spectroscopy (EDS) (Fig.4).Fig. 4 shows the microstructures of Pt/CNT 60. Observation of microstructure shows that the particle has a good particle homogeneity and uniform in across the sample surface.
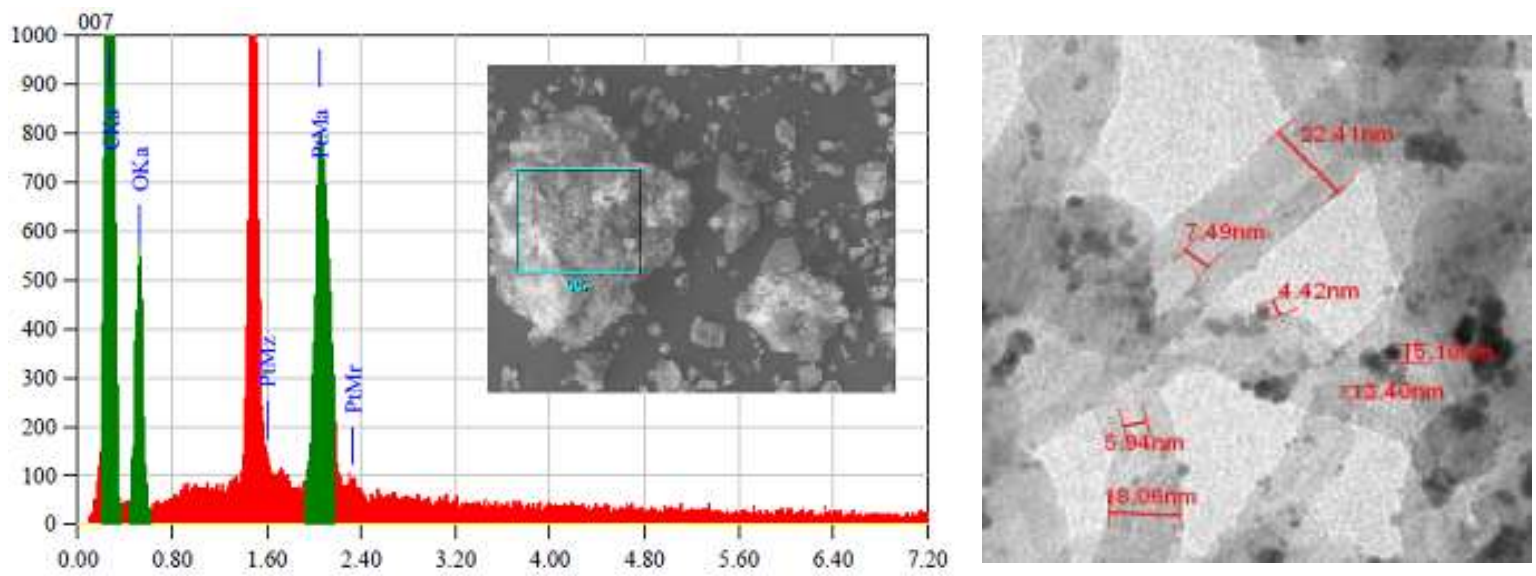

Figure 4. Elemental Analysis of Pt/CNT 60 by using Energy Dispersive Spectroscopy and The Image of Transmission Electron Microscopy (TEM) of Pt/ CNT 60

The energy spectrum of Pt/CNT 60 (Fig. 4) shows the presence of elements platinum (Pt), carbon (C) and oxygen (O) in $\mathrm{Pt} / \mathrm{CNT} 60$ about 62.9; 23.95; and 13.15w\%, respectively. Pt size is a relatively small around nano-sized scale. This size can be predicted from the comparison scale shown in the image of transmission electrom microscopy (TEM) as Fig.6. The average particle size for Pt nano particle is estimated to range from 4.1-4.3 nm. While the cavity diameter average of CNT is estimated to range from 5.9-7.5 nm. A comparative study of the mean crystallite size of $\mathrm{Pt}$ obtained from XRD is also reported. In the Williamson Hull formula, the crystallite size (D) of Pt have been obtained from FWHM by using Williamson Hull relation. The plot of FWHM (rad) $\operatorname{Cos} \theta$ (axis-y) versus $\operatorname{Sin} \theta$ (axis-x) corresponding to the four strongest peaks of Pt shown in Fig. 5 is a straight line. The slope and intercept of linearly fitted data give amounts of crystallite size. Crystallite size using Williamson Hull curve was estimated about $4.31 \mathrm{~nm}$.

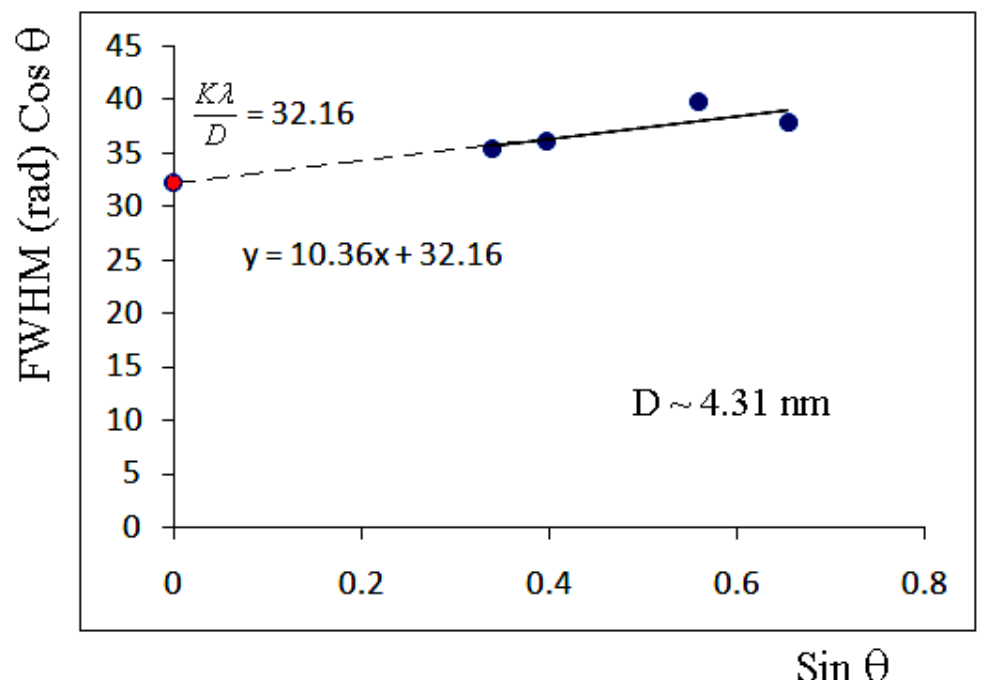

Figure 5. Crystallite size of CNT/Pt 60 based on a WilliamsonHull Curve

Based on the results of the TEM observation and calculation, crystallite size of Pt particle is equal which suggests a phenomenon of a single crystal Pt. It means that the Pt nanoparticles will have properties that approach the excellent properties of single crystals. This result is also equals that obtained by Jiehua (Yudianti \& Onggo, 2012) which displays that particles Pt has an ultrafine size $(3-6 \mathrm{~nm})$ and a very narrow size distribution were coated on surface of CoCNTs. The crystal size of $\mathrm{Pt}$ in $\mathrm{Pt} / \mathrm{CoCNT}$ is $\sim 5 \mathrm{~nm}$ using Scherrer equation based on XRD curve. This is concluded that this 
study has been successfully carried out to disperse Pt nanoparticles into CNT formed Pt/CNT composite was a great opportunity that the material can be applied as membrane electrodes on fuel cell application.

\section{Conclusion}

This research successfully carried out dispersion of Pt nanoparticles on CNT surface formed Pt/CNT composite. The refinement results of $\mathrm{x}$-ray diffraction pattern showed the sample consisted of two phases, namely, carbon and platinum phases. Carbon phase has a structure hexagonal $(\mathrm{P} 63 \mathrm{~m} \mathrm{c}$ ) with lattice parameters $\mathrm{a}=\mathrm{b}=2.451(2) \AA$ and $\mathrm{c}=6.89(1)$ $\AA, \alpha=\beta=90^{\circ}$ and $\gamma=120^{\circ}$, the unit cell volume of $\mathrm{V}=35.8(1) \mathrm{A}^{3}$, and the atomic density of $=2.224 \mathrm{gr}_{\mathrm{cm}}{ }^{-3}$. While platinum phase has the structure of cubic ( $\mathrm{F} \mathrm{m} \mathrm{-3} \mathrm{m)} \mathrm{with} \mathrm{lattice} \mathrm{parameters} \mathrm{a}=\mathrm{b}=\mathrm{c}=3.921(2) \AA, \alpha=\beta=\gamma=90^{\circ}$, the unit cell volume of $\mathrm{V}=60.3(1) \mathrm{A}^{3}$, and the atomic density of $\rho=21.487 \mathrm{gr.cm}^{-3}$. According to the image of transmission electron microscopy, the average particle size for Pt nanoparticle is estimated in range from 4.1-4.3 nm. While the cavity diameter average of CNT is estimated in range from 5.9-7.5 $\mathrm{nm}$. The calculation result that the crystallite size of the Pt particle was around $4.31 \mathrm{~nm}$. The optimum value of dispersed Pt into CNT occurred at $60 \mathrm{wt} \%$ CNT content.

\section{References}

Aouissi, A., Al-Suhybani, A. A., Al-Mayouf, A. M., \& Saleh, M. S. A. (2014). Preparation and Characterization of Carbon Nanotubes-Supported Pt-SiW12O40 Catalyst for Electrooxidation of Cyclohexane to Cyclohexanone/Cyclohexanol. Int. J. Electrochem. Sci., 9, 2762-2774.

Aritonang, H. F., Onggo, D., Ciptati, C., \& Radiman, C. L. (2014). Synthesis of Platinum Nanoparticles from K2PtCl4 Solution Using Bacterial Cellulose Matrix, Journal of Nanoparticles, 2014, Article ID 285954, 1-6.

Debe, M. K. (2012). Electrocatalyst approaches and challenges for automotive fuel cells. Nature, 486(7401), 43-51. https://doi.org/10.1038/nature11115

Flegler, S. L., Heckman Jr, J. W., \& Kl omparens, K. L. (1993). Scanning and Transmission Electron Microscopy, New York: W. H. Freeman and Company.

Idris, M. S., \& Osman, R. A. M. (2013). Structure Refinement Strategy of Li-Based Complex Oxides Using GSAS-EXPGUI Software Package. Advanced Materials Research, 795, 479-482. https://doi.org/10.4028/www.scientific.net/AMR.795.479

Liu, J., Shen, A., Wei, X., Zhou, K., Chen, W., Chen, F., ... \& Dai, L. (2015). Ultrathin Wrinkled N-Doped Carbon Nanotubes for Noble-Metal Loading and Oxygen Reduction Reaction. ACS Appl. Mater. Interfaces, 7, 20507-20512. https://doi.org/10.1021/acsami.5b07554

Luo, C., Xie, H., Wang, Q., Luo, G., \& Liu, C. (2015). A Review of the Application and Performance of Carbon Nanotubes in Fuel Cells. Journal of Nanomaterials, 2015, Article ID 560392, 1-10.

Monshi, A., Foroughi, M. R., \& Monshi, M. R. (2012). Modified scherrer equation to estimate more accurately nano-crystallite size using XRD. World Journal of Nano Science and Engineering, 2, 154-160. https://doi.org/10.4236/wjnse.2012.23020

Rao, C. V., \& Ishikawa, Y. (2012). Activity, selectivity, and anion-exchange membrane fuel cell performance of virtually, metal-free nitrogen-doped carbon nanotube electrodes for oxygen reduction reaction. The Journal of Physical Chemistry C., 116(6)6, 4340-4346. https://doi.org/10.1021/jp210840a

Rao, C. V., \& Viswanathan, B. (2010). Monodispersed platinum nanoparticle supported carbon electrodes for hydrogen oxidation and oxygen reduction in proton exchange membrane fuel cells. Journal of Physical Chemistry C. Vol. 114(18), 8661-8667. https://doi.org/10.1021/jp101481g

Sharma, R. K., Tiwari, B., \& Tomar, J. S. (2014). Study of Thermal Stability of Metal Carbon Nanotubes by SEM, XRD \& TGA. International Journal of Innovative Research in Science, Engineering and Technology, 3(2), 9081-9084.

Shi, R., Wang, J., Cheng, N., Sun, X., Zhang, L., Zhang, J. J., \& Wang, L. C. (2014). Electrocatalytic activity and stability of carbon nanotubes-supported Pt-on-Au, Pd-on-Au, Pt-on-Pd-on-Au, Pt-on-Pd, and Pd-on-Pt catalysts for methanol oxidation reaction. Electrochimica Acta., 148, 1-7. https://doi.org/10.1016/j.electacta.2014.10.036

Toby, B. H. (2001). EXPGUI, a graphical user interface for GSAS. Journal of Applied Crystallography, 34, 210. https://doi.org/10.1107/S0021889801002242

Valenzuela-Mũniz, A. M., Alonso-Nũnez, G., Botte, G. G., Miki-Yoshida, M., \& Verde-G’omez, Y. (2014). Influence of nickel on the electrochemical activity of PtRu/multiwalled carbon nanotubes electrocatalysts for directmethanol fuel cells. Journal of Applied Electrochemistry, 44(6), 695-700. https://doi.org/10.1007/s10800-014-0679-X 
Wan, K., Long, G., Liu, M., Du, L., Liang, Z., \& Tsiakaras, P. (2015). Nitrogen-doped ordered mesoporous carbon: synthesis and active sites for electrocatalysis of oxygen reduction reaction. Applied Catalysis B: Environmental, 165, 566-571. https://doi.org/10.1016/j.apcatb.2014.10.054

Wu, Y., Liao, S., Wang, K., Chen, M., \& Birss, V. (2010). High pressure organic colloid method for the preparation of high performance carbon nanotube-supported $\mathrm{Pt}$ and PtRu catalysts for fuel cell applications. Science in China Series E: Technological Sciences, 53(1), 264-271. https://doi.org/10.1007/s11431-009-0330-y

Yudianti, R., \& Onggo, H. (2012). Role of Catalytic Synthesis on Growth and Distribution of Platinum Nanoparticle on Carbon Nanotube Surface. Journal of Nanoscience and Technology, 2(6), 171-177.

Zhao, L., Wang, Z., Li, J., Zhang, J., Sui, X., \& Zhang, L. (2015). A newly-designed sandwich-structured graphene-Pt-graphene catalyst with improved electrocatalytic performance for fuel cells. Journal of Materials Chemistry A., 3(10), 5313-5320. https://doi.org/10.1039/C4TA06172A

\section{Copyrights}

Copyright for this article is retained by the author(s), with first publication rights granted to the journal.

This is an open-access article distributed under the terms and conditions of the Creative Commons Attribution license (http://creativecommons.org/licenses/by/4.0/). 